\title{
Metabolic syndrome in pregnancy and postpartum: prevalence and associated factors
}

\author{
(iD) Maria do Carmo Pinto Lima ${ }^{\mathbf{1 , 2}}$ \\ Adriana Suely Oliveira Melo ${ }^{1}$ \\ (iD) Aline Silva Santos Sena $\mathbf{1}^{\mathbf{1}}$ \\ (iD) Vivianne de Oliveira Barros ${ }^{1,2}$ \\ (iD) Melania Maria Ramos Amorim ${ }^{\mathbf{1 , 2}}$
}

1. Instituto Paraibano de Pesquisa Joaquim Amorim Neto (IPESQ), Campina Grande, PB, Brasil. 2. Instituto de Medicina Integral Prof. Fernando Figueira (IMIP), Recife, PE, Brasil.

\section{SUMMARY}

OBJECTIVE: Evaluate the prevalence of metabolic syndrome (MS) and the main associated maternal factors in women without pre-gestational conditions, in early pregnancy and in the immediate postpartum.

METHODS: Two hundred pregnant women were evaluated at the $16^{\text {th }}$ week of pregnancy, and 187 were reassessed postpartum. MS was diagnosed according to the criteria by the National Cholesterol Education Program Adult Treatment Panel III. In addition to the diagnostic criteria, anthropometric measures, blood pressure, metabolic profile, and visceral and subcutaneous fat thickness (by ultrasonography) were collected from the pregnant woman. The student's t-test was used to compare the prevalence of MS and its components in the $16^{\text {th }}$ week and in the postpartum. Multiple logistic regression was performed to identify the principal factors associated with the syndrome.

RESULTS: The prevalence of the MS was 3.0\% in early pregnancy and $9.7 \%$ postpartum ( $p=0.01)$. Following multiple logistic regression, the prepregnancy body mass index (BMI) $(p=0.04)$ and high-density lipoprotein cholesterol $(H D L-c)(p=0.02)$ remained associated with MS at 16 weeks, and triglyceride levels evaluated in postpartum ( $p<0.001)$ with MS in postpartum.

CONCLUSION: The frequency of the MS was high in the immediate postpartum. The factors associated were prepregnancy BMI and $H D L-c$ at the $16^{\text {th }}$ week, as well as triglyceride levels postpartum.

KEYWORDS: Metabolic syndrome. Pregnancy. Postpartum period. Risk factors.

\section{INTRODUCTION}

Metabolic syndrome(MS) is defined by the National Cholesterol Education Program Adult Treatment Panel III (NCEP-ATP III) as the presence of at least three of the following characteristics: abdominal obesity (abdominal circumference $\geq 88 \mathrm{~cm}$ ), triglycerides $\geq 150 \mathrm{mg} / \mathrm{dL}$, cholesterol, high-density lipoprotein cholesterol (HDL-c) $<50 \mathrm{mg} / \mathrm{dL}$, blood pressure (BP) $\geq 130 / 85 \mathrm{mmHg}$, and fasting glycemia $\geq 100 \mathrm{mg} / \mathrm{dL}^{1}$. Different criteria, however, are being used to classify the syndrome during pregnancy and in the postpartum period, when the abdominal circumference is significantly changed. ${ }^{2-4}$ 
Despite the contradictions regarding classification in these periods, studies showed a prevalence of MS of $12.4 \%$ in pregnant women and $29 \%$ in puerperal women. ${ }^{5.6}$ The factors often associated with the syndrome were age, parity, dyslipidemia, gestational diabetes mellitus (GDM), hypertension, and obesity. ${ }^{5,6-9}$

The high prevalence found by the studies, the metabolic risks from the physiological changes of pregnancy and the postpartum period, the lack of established parameters to classify the syndrome, and the inconsistencies regarding its prevalence and associated factors in women with no previous diseases suggest the need for research on the topic. Thus, the objective of this study was to evaluate the prevalence of MS and the main maternal factors associated with it in women without pre-gestational diseases, at the beginning of pregnancy and in the immediate postpartum period.

\section{METHODS}

\section{Study design}

This is a cohort study with 200 pregnant women treated in basic health units of the city of Campina Grande, Paraíba, Brasil. The women were evaluated in the 16th week of gestation $(\mathrm{n}=200)$ and re-evaluated during the immediate postpartum period $(\mathrm{n}=187)$ in the Instituto Paraibano de Pesquisa Professor Joaquim Amorim Neto (IPESQ), between September 2014 and December 2015. The research was approved by the Research Ethics Committee of the Federal University of Paraíba (CAAE: 03649512.9.0000.5182), and all participants signed an informed consent form (ICF).

\section{Sample Size}

The sample size was calculated by the OpenEpi, version 2.3 (Atlanta, GA, USA), assuming a rate of waist circumference increase of $22.8 \%$ in the immediate postpartum. ${ }^{6}$ For a $85 \%$ power and a $95 \%$ confidence level, 148 pregnant women would have to be included. This number was increased by $30 \%$ to compensate for possible losses during follow-up.

\section{Eligibility criteria}

We included pregnant women, confirmed by ultrasound, with gestational age less than or equal to 16 weeks. We excluded women with pre-gestational diabetes mellitus (DM), suffering from psychiatric disorders, chronic maternal diseases (hypertension, heart disease, kidney disease, epilepsy, kidney failure), congenital malformations, and multiple pregnancies.

\section{Data collection and procedures performed}

In the 16th week of gestation ( \pm 1 week), after signing the ICF, the women underwent an ultrasound to confirm their pregnancy and answered a questionnaire with information about biological, sociodemographic, and obstetric characteristics. Next, we evaluated the diagnostic criteria for MS, its prevalence, and the possibly related maternal risk factors.

MS was diagnosed according to the classification by the NCEP/ATP III ${ }^{1}$ and the maternal factors investigated were the thicknesses of visceral and subcutaneous fat, anthropometric measurements, blood pressure (BP), and metabolic profile. After these assessments, the pregnant women were scheduled to return at the 28 th week and the immediate postpartum period ( $\leq 10$ days after delivery). In the 28 th week, we carried out only the oral glucose tolerance test (OGTT) and, in the postpartum period, were repeated all previous assessments.

The ultrasound was carried out by the same professional, a specialist in fetal medicine, who also measured the thickness of visceral and subcutaneous fat, according to the technique described by Armellini et al. ${ }^{10}$. The maternal BP was measured by the recommended palpation and auscultation methods. ${ }^{11}$

The anthropometric assessment included weight, height, body mass index (BMI), weight gain, circumferences of the waist, arm, and thigh, and the triceps and suprailiac skinfolds. Based on their BMI, the women were classified as underweight, average weight, overweight, or obese. ${ }^{12}$ The weight gain was obtained from the difference between the women's weight in each of these moments and their pre-gestational weight self-reported during the filling out of the questionnaire. The circumferences of the waist, arm, and thigh, and the skinfolds were evaluated according to Jackson and Pollock. ${ }^{13}$

The biochemical measurements included total cholesterol, HDL-c, low-density lipoprotein cholesterol (LDL-c), triglycerides, insulin, homeostasis model assessment (HOMA-IR), and levels of fasting glucose. Insulin resistance was determined according to the HOMA-IR [fasting insulin $(\mathrm{mUI} / \mathrm{ml}) \times$ fasting glucose $(\mathrm{mmol} / \mathrm{l}) / 22.5] .^{14}$

At the 28th week of gestation, the women returned to the PESQ to undergo the OGTT, as previously scheduled. The diagnosis of gestational diabetes mellitus (GDM) was based on the confirmed fasting glycemia $\geq 92 \mathrm{mg} / \mathrm{dl}$ at the 16th week of gestation, in addition to an OGTT with any of the following abnormal values: 
fasting glycemia $\geq 92 \mathrm{mg} / \mathrm{dl}$; one-hour levels $\geq 180 \mathrm{mg} /$ $\mathrm{dl}$, and two-hour levels $\geq 153 \mathrm{mg} / \mathrm{dl}^{14}$

\section{Data Analysis}

Medcalc, version 15.6.1. (Medical Software bvba, Ostend, Belgium), and Epi Info, version 7.1.5 (Atlanta, GA, USA) were used for the statistical analysis. The Student $t$-test was used to compare the prevalence of metabolic syndrome and its components in these periods. A bivariate analysis was then performed to test the association between the variables studied and MS (ANOVA and Kruskal-Wallis Test). Stepwise logistic regression was performed to identify the main maternal factors associated with the syndrome, including the variables that remained associated with a significance level of $20 \%$ in the bivariate analysis. The final model included only the variables that remained associated with the outcomes at a significance level of $5 \%$.

\section{RESULTS}

The prevalence of MS at the 16th week was 3.0\% $(\mathrm{n}=6)$ in comparison to $9.7 \%(\mathrm{n}=18)$ during the immediate postpartum period $(\mathrm{p}=0.01)$. Regarding the criteria for MS classification at the 16th week, the frequency of abdominal obesity (abdominal circumference $\geq 88$ $\mathrm{cm}$ ), HDL-c $<50 \mathrm{mg}$, triglycerides $\geq 150 \mathrm{mg} / \mathrm{L}$, fasting glycemia $\geq 100 \mathrm{mg} / \mathrm{dL}$, and $\mathrm{BP} \geq 130 / 85 \mathrm{mmHg}$ was $100 \%$ and $34 \%(\mathrm{p}<0.001), 83.3 \%$ and $40.7 \%(\mathrm{p}=0.02), 83.3 \%$ and $11.8 \%(\mathrm{p}<0.001), 0 \%$ and $0.5 \%(\mathrm{p}=0.84)$, and $0 \%$ and $1 \%(\mathrm{p}=0.93)$ in the groups with and without the syndrome, respectively (Table 1). During the immediate post-partum period, the frequencies were $77.8 \%$ and $40.8 \%$ ( $\mathrm{p}<0.001) ; 88.9 \%$ and $39 \%$ ( $\mathrm{p}<0.001) ; 83.3 \%$ and $11.2 \%$ ( $\mathrm{p}<0.001) ; 0 \%$ and $1.2 \%$ ( $\mathrm{p}=0.84) ; 16.6 \%$ and $2.9 \%$ $(\mathrm{p}=0.01)$, in both groups (Table 1).

The mean age in the groups with and without MS were $31.5 \pm 8.4$ and $25.4 \pm 5.7$ years at the 16 th week of gestation $(p=0.01)$. In the postpartum period, these averages were $27.0 \pm 7.8$ and $25.6 \pm 5.6$ years in both groups, respectively $(\mathrm{p}=0.38)$. With respect to formal education, in both periods, the averages were $6.6 \pm 3.0$ and $9.7 \pm 3.8$ years at the 16 th week, and $8.8 \pm 3.2$ and $9.8 \pm 3.9$ years in the postpartum period for the groups with and without the syndrome $(p=0.05 ; p=0.32)$ (Table 2).

Regarding the reproductive history of the women, those with MS at the 16th week of pregnancy had an average of $3.8 \pm 2.3$ pregnancies, $0.0 \pm 0.5$ abortions, and $2.5 \pm 2.3$ deliveries compared with $2.0 \pm 1.2$ pregnancies, $0.2 \pm 0.5$ abortions, and $0.8 \pm 1.1$ deliveries by the women without the syndrome $(p=0.01 ; p=0.46 ; p<0.001$, respectively). In the postpartum period, the averages were of $2.7 \pm 1.6$ pregnancies, $0.3 \pm 0.6$ abortions, and $1.4 \pm 1.6$ deliveries in the group with MS, while in the group without the syndrome the averages were 2.0 \pm 1.1 pregnancies, $0.2 \pm 0.5$ abortions, and $0.7 \pm 0.9$ deliveries $(p=0.02 ; p=0.82$; and $p=0.04$, respectively). The average interval between pregnancies, at the 16 th week, was $4.2 \pm 2.3$ and $3.5 \pm 3.3$ years in both groups $(\mathrm{p}=0.64)$, at the same time, compared to $3.5 \pm 2.4$ and $3.4 \pm 3.4$ years $(\mathrm{p}=0.89)$ in the postpartum period (Table 2$)$.

As to the nutritional status of the women, 13.0\% $(n=26)$ were classified with low weight at the 16 th week of gestation, compared to $1.3 \%(n=2)$ in the postpartum period $(\mathrm{p}<0.001) ; 48.7 \%(\mathrm{n}=91)$ and $57.3 \%$ $(\mathrm{n}=107)$ were classified as eutrophic in both periods $(\mathrm{p}=0.20)$, and the women considered overweight or obese were $38.1 \%(n=76)$ and $41.3 \%(n=77)(p=0.62)$, respectively.

The average maternal weight in the groups with and without the syndrome was $72.4 \pm 15.4 \mathrm{~kg}$ and $62.4 \pm 11.2 \mathrm{~kg}(\mathrm{p}=0.03)$ at the 16 th week of gestation, while in the postpartum period, it was $68.7 \pm 15.1 \mathrm{~kg}$ and $65.0 \pm 10.3 \mathrm{~kg}(\mathrm{p}<0.20)$ (Table 3). The mean BMI was $28.3 \pm 5.1$ and $24.5 \pm 4.0(p<0.001)$ at the 16 th week of gestation when compared to $28.3 \pm 3.0$ and $25.7 \pm 4.1$ $(\mathrm{p}=0.01)$ in the postpartum period (Table 2). There was

TABLE 1. DIAGNOSTIC CRITERIA FOR MS, ACCORDING TO THE NCEP/ATP III CLASSIFICATION, IN WOMEN WITH AND WITHOUT THE SYNDROME. CAMPINA GRANDE, PARAÍBA, BRASIL, 2015.

\begin{tabular}{|c|c|c|c|c|c|c|c|}
\hline & \multicolumn{3}{|c|}{ MS at the 16 th week $(n=200)$} & \multicolumn{3}{|c|}{$\begin{array}{l}\text { MS in the immediate postpartum } \\
\text { period }(n=187)\end{array}$} & \multirow[t]{2}{*}{$\mathrm{p} \#$} \\
\hline & Yes \% & No $\%$ & p-value & Yes \% (n) & No \% (n) & p-value ${ }^{*}$ & \\
\hline Abdominal circumference $\geq 88 \mathrm{~cm}$ & $100(6)$ & $34(66)$ & $<0.001$ & $77.8(14)$ & $40.8(69)$ & $<0.001$ & 0.02 \\
\hline $\mathrm{HDL}-\mathrm{c}(\mathrm{mg} / \mathrm{dl})<50 \mathrm{mg} / \mathrm{dL}$ & $83.3(5)$ & $40.7(79)$ & 0.02 & $88.9(16)$ & $39(66)$ & $<0.001$ & 0.49 \\
\hline Triglycerides $(\mathrm{mg} / \mathrm{dl}) \geq 150 \mathrm{mg} / \mathrm{dL}$ & $83.3(5)$ & $11.8(23)$ & $<0.001$ & $83.3(15)$ & $11.2(19)$ & $<0.001$ & 0.05 \\
\hline Fasting blood glucose $(\mathrm{mg} / \mathrm{dl}) \geq 100 \mathrm{mg} / \mathrm{dL}$ & $0(0)$ & $0.5(1)$ & 0.84 & $\mathrm{O}(0)$ & $1.2(2)$ & 0.84 & 0.92 \\
\hline $\mathrm{BP} \geq 130 / 85 \mathrm{mmHg}$ & $\mathrm{O}(0)$ & $1(2)$ & 0.93 & $16.6(3)$ & $2.9(5)$ & 0.01 & 0.15 \\
\hline
\end{tabular}

MS: Metabolic syndrome; HDL-c: high-density lipoprotein cholesterol; BP: Blood pressure; *ANOVA. \# Student's t-test. 
TABLE 2. BIOLOGICAL, ANTHROPOMETRIC, AND SOCIODEMOGRAPHIC CHARACTERISTICS, VISCERAL AND SUBCUTANEOUS FAT, AND METABOLIC PROFILE OF WOMEN WITH AND WITHOUT MS. CAMPINA GRANDE, PARAÍBA, BRASIL, 2015 .

\begin{tabular}{|c|c|c|c|c|c|c|c|}
\hline & \multicolumn{3}{|c|}{ MS at the 16 th week $(n=200)$} & \multicolumn{3}{|c|}{$\begin{array}{l}\text { MS in the immediate postpartum period } \\
\qquad(n=187)\end{array}$} & \multirow[t]{2}{*}{$p$} \\
\hline & Yes $\%$ & No $\%$ & $\mathrm{p}$ & Yes \% & No $\%$ & $\mathrm{p}$ & \\
\hline Age & $31.5 \pm 8.4$ & $25.4 \pm 5.7$ & 0.01 & $27.0 \pm 7.8$ & $25.6 \pm 5.6$ & 0.38 & 0.80 \\
\hline Formal education & $6.6 \pm 3.0$ & $9.7 \pm 3.8$ & 0.05 & $8.8 \pm 3.2$ & $9.8 \pm 3.9$ & 0.32 & 0.02 \\
\hline Pregnancies & $3.8 \pm 2.3$ & $2.0 \pm 1.2$ & $0.01^{\#}$ & $2.7 \pm 1.6$ & $2.0 \pm 1.1$ & $0.02^{\#}$ & 0.79 \\
\hline Abortions & $0.0 \pm 0.5$ & $0.2 \pm 0.5$ & $0.46^{\#}$ & $0.3 \pm 0.6$ & $0.2 \pm 0.5$ & $0.82^{\#}$ & 0.79 \\
\hline Birth interval & $4.2 \pm 2.3$ & $3.5 \pm 3.3$ & 0.64 & $3.5 \pm 2.4$ & $3.4 \pm 3.4$ & 0.89 & 0.07 \\
\hline Parity & $2.5 \pm 2.3$ & $0.8 \pm 1.1$ & $<0.001^{\#}$ & $1.4 \pm 1.6$ & $0.7 \pm 0.9$ & $0.04^{\#}$ & 0.23 \\
\hline Visceral Fat & $5.9 \pm 1.2$ & $5.2 \pm 1.3$ & 0.20 & $5.5 \pm 1.9$ & $5.6 \pm 1.5$ & 0.83 & 0.83 \\
\hline Subcutaneous fat & $2.9 \pm 0.8$ & $2.3 \pm 0.8$ & 0.07 & $3.0 \pm 1.0$ & $2.4 \pm 0.8$ & 0.01 & 0.01 \\
\hline Systolic BP & $116.8 \pm 4.6$ & $112.5 \pm 10.4$ & 0.35 & $123.4 \pm 17.8$ & $115.0 \pm 11.0$ & 0.02 & 0.02 \\
\hline Diastolic BP & $66.8 \pm 14.1$ & $68.2 \pm 9.6$ & 0.74 & $81.0 \pm 12.2$ & $74.4 \pm 10.4$ & 0.04 & 0.04 \\
\hline Pre-gestational BMI & $29.0 \pm 5.7$ & $24.4 \pm 4.3$ & 0.01 & $28.0 \pm 5.7$ & $24.1 \pm 4.0$ & $p<0.00$ & 0.02 \\
\hline Height & $1.5 \pm 0.0$ & $1.5 \pm 0.6$ & 0.18 & $1.5 \pm 0.6$ & $1.8 \pm 0.6$ & 0.63 & 0.13 \\
\hline Weight & $72.4 \pm 15.4$ & $62.4 \pm 11.2$ & 0.03 & $68.7 \pm 15.1$ & $65.2 \pm 10.3$ & 0.20 & 0.20 \\
\hline $\mathrm{BMI}$ & $28.3 \pm 5.1$ & $24.5 \pm 4.0$ & $<0.001$ & $28.3 \pm 3.0$ & $25.7 \pm 4.1$ & 0.01 & $<0,001$ \\
\hline Weight gain & $14.4 \pm 12.6$ & $208.3 \pm 8.3$ & 0.27 & $1.1 \pm 6.9$ & $4.8 \pm 4.9$ & $<0.001$ & 0.03 \\
\hline Waist circumference & $98.9 \pm 12.4$ & $88.0 \pm 9.6$ & $<0.001$ & $98.6 \pm 8.5$ & $91.9 \pm 9.5$ & $<0,001$ & $<0,001$ \\
\hline Arm circumference & $34.1 \pm 6.3$ & $28.0 \pm 3.4$ & $<0,001$ & $29.4 \pm 2.3$ & $28.5 \pm 3.1$ & 0.13 & 0.13 \\
\hline Thigh circumference & $30.8 \pm 11.1$ & $29.6 \pm 7.7$ & 0.72 & $41.7 \pm 10.1$ & $38.2 \pm 9.2$ & 0.21 & 0.21 \\
\hline Suprailiac fold & $30.3 \pm 16.4$ & $22.8 \pm 8.9$ & 0.05 & $26.2 \pm 7.8$ & $22.6 \pm 6.0$ & 0.03 & 0.05 \\
\hline Triceps fold & $28.1 \pm 11.5$ & $21.3 \pm 5.6$ & $<0.001$ & $26.2 \pm 7.8$ & $22.6 \pm 6.0$ & 0.03 & 0.03 \\
\hline Total cholesterol & $195.3 \pm 10.0$ & $168.6 \pm 30.9$ & 0.03 & $209.4 \pm 47.4$ & $215.0 \pm 42.6$ & 0.62 & 0.62 \\
\hline Fasting glucose & $67.5 \pm 4.4$ & $70.2 \pm 15.5$ & 0.66 & $73.0 \pm 11.7$ & $69.3 \pm 8.6$ & 0.12 & 0.61 \\
\hline Insulin & $9.3 \pm 5.8$ & $5.7 \pm 4.0$ & 0.03 & $7.1 \pm 4.9$ & $5.5 \pm 3.6$ & 0.13 & 0.13 \\
\hline HDL-c & $50.5 \pm 11.2$ & $45.0 \pm 2.5$ & 0.23 & $49.8 \pm 10.5$ & $39.0 \pm 6.5$ & $<0.001$ & $<0,001$ \\
\hline LDL-c & $106.6 \pm 16.7$ & $96.8 \pm 24.8$ & 0.32 & $121.7 \pm 46.5$ & $143.0 \pm 39.6$ & 0.06 & 0.06 \\
\hline Triglycerides & $218.1 \pm 51.7$ & $108.5 \pm 53.1$ & $<0,001$ & $245.0 \pm 92.3$ & $111.5 \pm 22.3$ & $<0.001$ & $<0,001$ \\
\hline HOMA-IR & $24.2 \pm 19.8$ & $14.3 \pm 14.4$ & 0.08 & $24.2 \pm 22.1$ & $17.4 \pm 12.0$ & 0.05 & 0.05 \\
\hline
\end{tabular}

MS: Metabolic syndrome; BMI: body mass index; GDM: gestational diabetes mellitus; BP: Blood pressure; HDL-c: high-density lipoprotein cholesterol; LDL-c: low-density lipoprotein cholesterol; HOMA-IR: model for the evaluation of homeostasis; IQR: interquartile interval. Values were expressed as mean \pm standard deviation. ${ }^{\star}$ Student's t-test. " Kruskal tein cholester

an association between maternal weight gain and the presence of $\mathrm{MS}(\mathrm{p}<0.001)$.

The average thickness of visceral fat was $5.9 \pm 1.2 \mathrm{~cm}$ and $5.2 \pm 1,3 \mathrm{~cm}(\mathrm{p}=0.20)$ at the 16 th week, while in the immediate post-partum period, it was $5.5 \pm 1.9 \mathrm{~cm}$ and $5.6 \pm 1.5 \mathrm{~cm}(\mathrm{p}=0.83)$ in the groups of women with and without MS (Table 2). No association was found between the thickness of visceral fat and the syndrome $(\mathrm{p}=0.88)$. The mean subcutaneous fat thickness was $2.9 \pm 0.8$ and $2.3 \pm 0.8(\mathrm{p}=0.07)$ at the 16 th week when compared to $3.0 \pm 1.0$ and $2.4 \pm 0.8(\mathrm{p}=0.01)$ in the postpartum period, in both groups, respectively (Table 2). An association was found between the subcutaneous fat and the presence of MS $(p<0.001)$.
TABLE 3. FINAL LOGISTIC REGRESSION MODEL FOR FACTORS ASSOCIATED WITH MS IN THE 16TH WEEK OF GESTATION AND IN THE IMMEDIATE POSTPARTUM PERIOD. CAMPINA GRANDE, PARAÍBA, BRASIL, 2015.

\begin{tabular}{|c|c|c|c|c|}
\hline & Odds Ratio & $95 \% \mathrm{Cl}$ & Coefficient & P-value \\
\hline \multicolumn{5}{|l|}{ 16th week $(n=200)$} \\
\hline Pre-gestational BMI & 1.08 & $1.00-1.17$ & 0.08 & 0.04 \\
\hline $\mathrm{HDL}-\mathrm{C}$ & 1.02 & $1.00-1.04$ & 0.02 & 0.02 \\
\hline \multicolumn{5}{|c|}{ Immediate postpartum $(n=187)$} \\
\hline $\begin{array}{l}\text { Triglycerides } \\
\text { (evaluated in the im- } \\
\text { mediate puerperium) }\end{array}$ & 1.04 & $1.01-1.07$ & 0.04 & $<0.001$ \\
\hline
\end{tabular}

* Stepwise logistic regression. 95\% Cl: 95\% confidence interval; BMI: body mass index; HDL-c: high-density lipoprotein cholesterol. 
Compared to the 16th week of gestation, in the postpartum period, there was a greater proportion of women that presented increased levels of fasting glucose $(0.5 \%$ and $1.3 \%)(\mathrm{p}=0.32)$, triglycerides $(16.3 \%$ and $22.6 \%)(p=0.60)$, total cholesterol (16.3\% and $63.2 \%)$ $(p=0.21)$, and LDL-c (44.4\% and $84.8 \%)(p=0.20)$ in the groups with and without MS. After analyzing both periods, the proportion of women with low levels of HDL-c increased slightly in the postpartum (58.2\%) when compared with the 16 th week $(57.0 \%)(p=0.03)$. The Frequency of GDM was $2.8 \%(n=5)$.

The mean levels of total cholesterol were $195.3 \pm 10.0 \mathrm{mg} / \mathrm{dl}$ and $168.6 \pm 30.9 \mathrm{mg} / \mathrm{dl}(\mathrm{p}=0.03)$ in women with and without metabolic syndrome at the 16 th week of gestation and $209.4 \pm 47,4 \mathrm{mg} / \mathrm{dl}$ and $215.0 \pm 42.6$ ( $p=0.62)$, simultaneously, in the postpartum period. The average of fasting glucose, after comparing both groups, were $67.5 \pm 4.4 \mathrm{mg} / \mathrm{dl}$ and $70.2 \pm 15.5$ $\mathrm{mg} / \mathrm{dl}(\mathrm{p}=0.66)$ at the 16 th week, while in the post-partum period, they were $73.0 \pm 11.7 \mathrm{mg} / \mathrm{dl}$ and $69.3 \pm 8.6$ $\mathrm{mg} / \mathrm{dl}(\mathrm{p}=0.12)$ (Table 2).

The average levels of insulin were $9.3 \pm 5.8 \mathrm{mUI} / \mathrm{ml}$ and $5.7 \pm 4.0 \mathrm{mUI} / \mathrm{ml}(\mathrm{p}=0.03)$ for women with and without MS at the 16th week of gestation, and $7.1 \pm 4.9 \mathrm{mUI} /$ $\mathrm{ml}$ and $5.5 \pm 3.6 \mathrm{mUI} / \mathrm{ml}(\mathrm{p}=0.13)$, respectively, in the postpartum period. Regarding the triglyceride levels in both groups, the averages were $218.1 \pm 51,7 \mathrm{mg} /$ $\mathrm{dl}$ and $108.5 \pm 53.1(\mathrm{p}<0.001)$ at the 16 th week, and $245.0 \pm 92,3 \mathrm{mg} / \mathrm{dl}$ and $111.5 \pm 22.3(\mathrm{p}<0.001)$ post-partum (Table 2). As for resistance to insulin, the mean HOMA-IR was $24.2 \pm 19.8$ and $14.3 \pm 14.4(\mathrm{p}=0.08)$ at the 16 th week of gestation, while during the post-partum period it was $24.2 \pm 22.1$ and $17.4 \pm 12.0(\mathrm{p}=0.05)$ in the groups with and without MS. (Table 2).

After logistic regression analysis, the pre-gestational BMI $(\mathrm{p}=0.04)$ and HDL-c $(\mathrm{p}=0.02)$ remained significantly associated with MS in the 16th week of gestation. In the postpartum period, only the levels of triglycerides, analyzed in this period, remained significantly associated with the syndrome $(p<0.001)$ (Table 3).

\section{DISCUSSION}

The prevalence of MS in the immediate postpartum was high when compared to that found at the beginning of pregnancy, and the only factors that remained associated with the syndrome were pre-gestational BMI, HDL-c at the 16th week, and triglycerides in the postpartum period.
A similar frequency of the syndrome in early pregnancy was reported in a study involving women at 12 weeks of gestation. ${ }^{15}$ However, a retrospective research with women at 14 to 16 weeks of gestation reported a much higher prevalence (12.3\%). ${ }^{5}$ This difference, however, may have resulted from the application of different criteria for the classification of MS. In fact, the researchers in that multicenter study used the parameters by the International Diabetes Federation (FID), which establish a cutoff point for waist circumference $(80 \mathrm{~cm})$ lower than that applied in this study ${ }^{5}$. Since there is a physiological change to that measurement during pregnancy, an even lower cutoff point could predispose more easily a high rate of MS diagnoses.

Postpartum studies also showed higher prevalence rates of MS in comparison to our results, reaching 39\%,6,9,15-17. However, this difference may be explained by the selection of the sample, since our study excluded pregnant women with associated morbidities because the objective was to understand the magnitude of the disease in pregnant women without pre-gestational diseases.

With respect to the weight and nutritional status of the pregnant women, those with MS presented excess weight, and the pre-gestational BMI remained significantly associated with MS in the 16 th week. Unlike our results, other studies showed an association between pre-gestational BMI indicative of overweight and obesity and the presence of MS in the postpartum period., ${ }^{9,16,18}$ In these studies, however, MS was diagnosed in the postpartum period in women with a diagnosis of GDM who, according to the pre-gestational BMI, were overweight/obese and whose levels of fasting glucose were high. $.16,18$

In relation to the biochemical analysis, only the levels of HDL-c in the 16th week and the triglyceride levels in the postpartum period remained significantly associated with MS in this study. Corroborating these findings, a study carried out at the beginning of the gestation showed higher average levels of triglycerides $(192.5 \pm 87.5 \mathrm{mg} / \mathrm{dl}$ and $105 \pm 61.2 \mathrm{mg} / \mathrm{dl})$ and lower HDL-c $(456.79 \pm 114.2 \mathrm{mg} /$ $\mathrm{dl}$ and $532.92 \pm 152.26 \mathrm{mg} / \mathrm{dl}$ ) in women with MS in comparison to those without it. ${ }^{4}$

Other studies have reported conflicting results, with findings of a correlation between MS and insulin resistance ${ }^{15}$ and between MS and hypertension; ${ }^{6,16,19}$ however, unlike in the present study, 
pregnant women with GDM and women with various degrees of glucose intolerance were included in these samples.

A limitation of this study is the risk of an overestimated prevalence of MS due to the difficulty in classifying it in both periods through the pre-established criteria. The strengths of this study are the homogeneity of the sample, the small number of losses, and the inclusion of healthy women.

Studies on metabolic syndrome and its associated risk factors in pregnant women can assist in predicting the disease during pregnancy and in the postpartum period, allowing the use of preventive strategies to reduce maternal and child damage in the short and long term.

\section{CONCLUSION}

The frequency of metabolic syndrome was higher during the immediate postpartum period, and a pre-gestational BMI indicative of overweight/obesity and abnormal levels of HDL-c at the 16th week of pregnancy, in addition to abnormal levels of triglycerides in the immediate post-partum period, seem to represent important risk factors for the development of metabolic syndrome in these periods.

No conflicts of interest. The study was approved in the Ethics and Research Committee by the CAAE: 03649512.9.0000.5182, on the 26/03/2014.

Funding: National Council for the Development of Science and Technology (CNPq).

\section{RESUMO}

OBJETIVO: Avaliar a prevalência da SM e os principais fatores maternos associados em mulheres sem doenças pré-gestacionais, no início da gravidez e no pós-parto imediato.

MÉTODOS: Foram avaliadas 200 mulheres na 16ª semana de gravidez, sendo 187 reavaliadas no pós-parto. A SM foi diagnosticada de acordo com os critérios do National Cholesterol Education Program Adult Treatment Panel III. Além dos critérios diagnósticos da síndrome, foram coletadas medidas antropométricas, pressão arterial, perfil metabólico e espessura de gordura visceral e subcutânea (através de ultrassonografia) da gestante. O teste t de Student foi usado para comparar a prevalência de SM e dos seus componentes nos dois momentos. Os modelos de regressão logística múltipla, para investigar os principais fatores associados à síndrome na $16^{a}$ semana de gestação e no pós-parto.

RESULTADOS: A prevalência da SM foi de 3,0\% no início da gravidez e 9,7\% no pós-parto ( $p=0,01)$. O índice de massa corporal (IMC) pré-gravídico $(p=0,04)$ e o colesterol lipoproteínas de alta densidade (HDL-c) $(p=0,02)$ permaneceram associados à SM na $16^{2}$ semana Após o parto, os níveis de triglicerídeos permaneceram associados à SM no pós-parto $(p<0,001)$.

CONCLUSÃO: A prevalência da SM foi alta no pós-parto imediato e os fatores associados à síndrome foram IMC pré-gravídico e HDL-C na $16^{a}$ semana, e níveis triglicerídeos no pós-parto.

PALAVRAS-CHAVES: Síndrome metabólica. Gravidez. Período pós-parto. Fatores de risco.

\section{REFERENCES}

1. Carson MP. Society for maternal and fetal medicine workshop on pregnancy as a window to future health: clinical utility of classifying women with metabolic syndrome. Semin Perinatol. 2015;39(4):284-9.

2. Hakkarainen $\mathrm{H}$, Huopio $\mathrm{H}$, Cederberg $\mathrm{H}$, Voutilainen $\mathrm{R}$, Heinonen $\mathrm{S}$. Future risk of metabolic syndrome in women with a previous LGA delivery stratified by gestational glucose tolerance: a prospective cohort study. BMC Pregnancy Childbirth. 2018;18(1):326.

3. Varner MW, Rice MM, Landon MB, Casey BM, Reddy UM, Wapner RJ, et al; Eunice Kennedy Shriver National Institute of Child Health and Human Development (NICHD) Maternal-Fetal Medicine Units (MFMU) Network. Pregnancies after the diagnosis of mild gestational diabetes mellitus and risk of cardiometabolic disorders. Obstet Gynecol. 2017;129(2):273-80.

4. Cho NH, Ahn CH, Lua JH, Kwak SH, Choi SH, Lim S, et al. Metabolic syndrome independently predicts future diabetes in women with a history of gestational diabetes mellitus. Medicine (Baltimore). 2016;95(35):e4582.
5. Grieger JA, Grzeskowiak LE, Smithers LG, Bianco-Miotto T, Leemaqz SY, Andraweera $P$, et al.. Metabolic syndrome and time to pregnancy: a retrospective study of nulliparous women. BJOG. 2019;126(7):852-62.

6. Rice MM, Landon MB, Varner MW, Casey BM, Reddy UM, Wapner RI, et al; Eunice Kennedy Shriver National Institute of Child Health and Human Development (NICHD) Maternal-Fetal Medicine Units Network (MFMU). Pregnancy-associated hypertension in glucose-intolerant pregnancy and subsequent metabolic syndrome. Obstet Gynecol. 2016;127(4):771-9.

7. Lee Y, Lee HN, KIM SJ, Koo J, Lee KE, Shin JE. Higher parity and risk of metabolic syndrome in Korean postmenopausal women: Korea National Health and Nutrition Survey 2010-2012. J Obstet Gynecol Res. 2018;44(11):2045-52.

8. Szostak-Wegierek D, Waśkiewicz A, Piotrowski W, Stepaniak U, Pająk A, Kwaśniewska M, et al. Metabolic syndrome and its components in Polish women of childbearing age: a nationwide study. BMC Public Health. 2017;18(1):15. 
9. Puhkala |, Raitanen |, Kolu P, Tuominen P, Husu P, Luoto R. Metabolic syndrome in Finnish women 7 years after a gestational diabetes prevention trial. BMI Open. 2017;7(3):e014565.

10. Armellini F, Zamboni M, Robbi R, Todesco T, Rigo L, Bergamo-Andreis IA et al. Total and intra-abdominal fat measurements by ultrasound and computerized tomography. Int | Obes Relat Metab Disord. 1993;17(4):209-14.

11. American College of Obstetricians and Gynecologists. Hypertension in pregnancy: executive summary. Obstet Gynecol. 2013;122(5):1122-31.

12. Atalah E, Castillo C, Castro R, Aldea A. Proposal of a new standard for the nutritional assessment of pregnant women. Rev Med Chil. 1997;125(12):1429-36

13. Jackson AS, Pollock ML. Generalized equations for predicting body density of men. 1978. Br | Nutr. 2004;91(1):161-8.

14. Standards of Medical Care in Diabetes-2017: summary of revisions. Diabetes Care. 2017:40(Suppl 1):S4-S5.
15. Horvath B, Bodecs T, Boncz |, Bodis |. Metabolic syndrome in normal and complicated pregnancies. Metab Syndr Relat Disord. 2013;11(3):185-8.

16. Nouhjah S, Shahbazian H, Shahbazian N, Jahanfar S, Jahanshahi A, Cheraghian $\mathrm{B}$, et al. Early postpartum metabolic syndrome in women with or without gestational diabetes: results from Life after Gestational Diabetes Ahvaz cohort study. Diabetes Metab Syndr. 2018;12(3):317-23.

17. Huvinen E, Eriksson JG, Koivusalo SB, Grotenfelt N, Tiitinen A, Stach-Lempinen $B$, et al. Heterogeneity of gestational diabetes (GDM) and long-term risk of diabetes and metabolic syndrome: findings from the RADIEL study follow-up. Acta Diabetol. 2018;55(5):493-501.

18. Barquiel B, Herranz L, Hillman N, Burgos MÁ, Pallardo LF. Prepregnancy body mass index and prenatal fasting glucose are effective predictors of early postpartum metabolic syndrome in Spanish mothers with gestational diabetes. Metab Syndr Relat Disord. 2014;12(9):457-63.

19. Yang ||, Lee SA, Choi IY, Song M, Han S, Yoon HS, et al. Subsequent risk of metabolic syndrome in women with a history of preeclampsia: data from the Health Examinees Study. | Epidemiol. 2015;25(4):281-8. 